\title{
Designing and study of X-ray emission from compact diode powered by capacitor discharge
}

\author{
Hamdullah khan
}

Department of Physics, BUITEMS, Quetta, Pakistan

Email address:

Hamdullah_khan@yahoo.com

\section{To cite this article:}

Hamdullah khan. Designing and Study of X-Ray Emission from Compact Diode Powered by Capacitor Discharge. American Journal of Physics and Applications. Vol. 1, No. 3, 2013, pp. 125-128. doi: 10.11648/j.ajpa.20130103.20

\begin{abstract}
A compact diode is designed and the parameters are specified for optimization of the diode. A comprehensive study of X-ray emission from compact diode, consisting of a sharp edged cathode and a flat anode of copper energized by a single capacitor charged up to $30 \mathrm{kV}$ is reported. The X-ray yield was measured as a function of the interelectrode spacing by using PIN-diode detectors. The maximum x-ray emission in is found to be $320 \mathrm{~mJ}$ and the corresponding average efficiency for the X-ray generation was about $0.05 \%$. The total X-ray yield in $4 \pi$ geometry was recorded as $850 \mathrm{~mJ}$ with an overall efficiency of about $0.136 \%$. The efficiency is expected to be further enhanced with an increase in discharge energy, charging voltage, and a reduction of the parasitic inductance.
\end{abstract}

Keywords: Compact Diode, X-Ray, Cathode, Pin Diode, Efficiency, Parasitic Inductance

\section{Introduction}

Substantial efforts have been made in recent years in the development of sub- microsecond and nanosecond pulsed $\mathrm{X}$-ray sources, due to their large number of potential applications. These sources are capable of a high power dose. Therefore such sources are very useful in the investigation of high-speed phenomena [1], bio-medical radiography [2], pre-ionization of a high-pressure gas discharge laser [3], photo-excitation of molecular [4] and atomic systems for fluorescence studies and time-resolved X-ray diffraction studies [5]. The recent available systems are based upon one of the three methodologies: synchrotrons [6], laser plasmas [7], and electron-beam discharges [8]. These systems are often large, complex, and expensive. The challenge is to develop small size systems, which generate short X-ray pulses at high repetition rate. In the last few years, attempts have been made to enhance Xray yield from plasma focus by adjusting different parameters, such as capacitor energy, charging voltage, circuit inductance, nature and pressure of working gases, material and shapes of electrodes, proper selection of anode length and insulator, and preionization before initial discharge in addition to normal operating conditions [9-10].

A conventional X-ray diode operates in vacuum with closely spaced electrodes, pow- ered with a high voltage capacitor discharge. Various kinds of X-ray generators, using different pulse forming networks with storage energies ranging between several hundreds of millijoules to several hundreds of joules, have been developed [11-12]. The bombardment of electrons on a solid target is the most important practical method for the generation of X-rays. When a suitable potential is applied, the thermionically emitted electrons are accelerated and then directed to some target. One may also attempt to operate an X-ray emitting diode employing field emission instead of thermionic emission technique.

Zakaullah and Worley [13] studied an X-ray emitting diode of impedance $2.3 \Omega$ with a knife-edge cathode energized by a $90-\mathrm{kV}, 30-\mathrm{J}$, solid dielectric Blumlein driver of 10-ns pulse length. X-ray emissions from titanium, copper, molybdenum, tin, tantalum, and lead anodes were analyzed. It was concluded that it may be used as characteristics or continuum radiation source of choice, and may find applications in various disciplines such radiography, crystallography, X-ray contact microscopy, and X-ray backlighting.

Shafiq et al. [14] investigated K-series line radiation emission of $\mathrm{Mo}$ and $\mathrm{Cu}$ from a low-energy Mather-type plasma focus. The maximum Mo and $\mathrm{Cu} \mathrm{K}$ series line emission of about $0.05 \mathrm{~J} / \mathrm{sr}$ and $0.17 \mathrm{~J} / \mathrm{sr}$ is observed at hydrogen filling pressure of 2.0 mbar. Total X-ray emission and efficiency in $4 \pi$ geometry are also obtained with values $4.12 \mathrm{~J}$ and $0.18 \%$ at 2.0 mbar. 
In this letter, we report the designing and x-ray emission from a compact diode energized by a high-inductance capacitor discharge is reported. Specifically, attention is paid to optimize the diode parameters for enhanced X-ray emission.

\section{Experimental Set Up}

The electrode system of compact diode consists of an anode, which is a flat plate of brass with the thickness of 10 $\mathrm{mm}$ and diameter of $30 \mathrm{~mm}$. At its surface, different metal targets may be mounted. The cathode is knife edged and is a replaceable piece of commercial needle. It is suspended in the chamber with a specially designed holder. The cathode holder is a brass plate of $30 \mathrm{~mm}$ diameter and $20 \mathrm{~mm}$ thickness, which is attached, with an outer brass plate of $257 \mathrm{~mm}$ diameter and $10 \mathrm{~mm}$ thickness. This outer

Plate is connected to the ground plate of the capacitor through six hexagonal brass rods used to reduce the inductance of the system. The anode header is connected to the high-voltage terminal of the capacitor through a spark gap (used as a switch). A schematic diagram of the compact diode system is shown in Fig. 1. The electrodes are enclosed in a cylindrical vacuum chamber made of an approximately $57 \mathrm{~mm}$ thick wall of ertlon with four openings/ports. One port is used to fit the capsule type (Edwards CG3) gauge to measure the vacuum in the chamber, and a rotary van pump is connected to the second port to obtain a vacuum upto $10^{-2} \mathrm{mbar}$, which is adequate in this experiment. The compact diode system is energized by a single $2 \mu \mathrm{F}, 30 \mathrm{kV}(900 \mathrm{~J})$ capacitor, with a discharge current of about $45 \pm 2 \mathrm{kA}$.

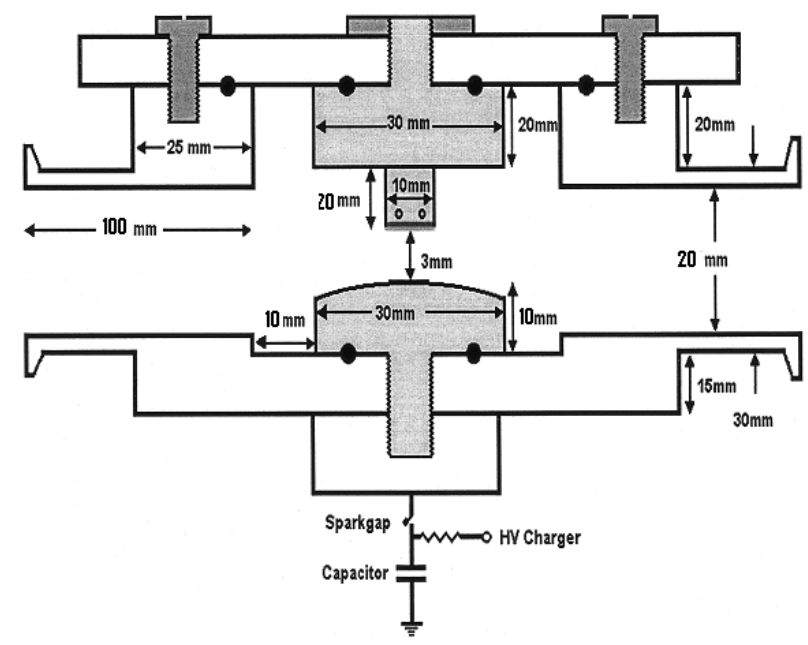

Fig 1. The schematic of compact diode electrode system.

To analyze the X-rays, two Quantrad PIN diodes that have a $100 \mathrm{~mm}^{2}$ effective area, with $125 \mu \mathrm{m}$-thick active layer masked with $\mathrm{Ni}(17.5 \mu \mathrm{m})$ and $\mathrm{Co}(20 \mu \mathrm{m})$ filters are used. The transmission, response curves of the filters set (17.5 $\mu \mathrm{m} \mathrm{Ni,} 20 \mu \mathrm{m} \mathrm{Co}$ ) along with response of the PIN diode and window response is given in Fig. 2. These curves are obtained by using the data given in the Handbook of Spectroscopy [15]. The Co filter has the absorption edge at $7.709 \mathrm{keV}$ and allows transmission of X-rays in the 4$7.709 \mathrm{keV}$ windows. The absorption edge of $\mathrm{Ni}$ lies at $8.333 \mathrm{keV}$ and allows transmission of the $\mathrm{Cu}-\mathrm{K} \alpha$ line of $8.047 \mathrm{keV}$. Thus the difference of transmission in the $\mathrm{Ni}$ and $\mathrm{Co}$ filters may be considered corresponding to the $\mathrm{Cu}-$ $\mathrm{K} \alpha$ line radiation. A four-channel 200-MHz GOULD 4074A oscilloscope and a computer are used to record electrical signals.
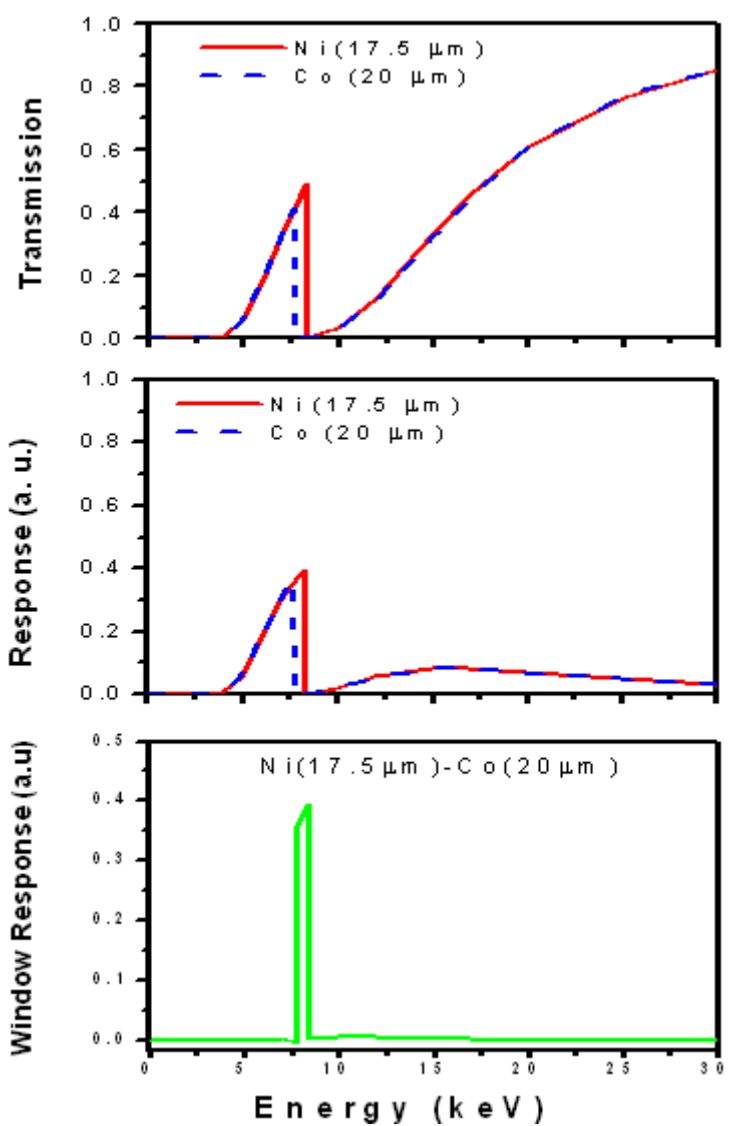

Figure 2. (a) Transmission curves of $N i(17.5 \mu \mathrm{m})$ and Co $(20 \mu \mathrm{m})$. (b) Detector (PIN-diode) response along with corresponding filters. (c) Window response of Ross filters obtained by the subtraction of Co $(20 \mu \mathrm{m})$ from $\mathrm{Ni}(17.5 \mu \mathrm{m})$ filter, the detector response is included.

\section{Results and Discussion}

Discharge in the compact diode is studied under a vacuum of $10^{-2} \mathrm{mbar}$ at different interelectrode spacing, with total discharge energy of $900 \mathrm{~J}$ at a fixed charging voltage of $30 \mathrm{kV}$. The sharp-edged needle is replaced, and the surface of the anode is cleaned every five shots. The peak discharge current $(45 \pm 2 \mathrm{kA})$ is recorded using the signal from the Rogowski coil. The total parasitic inductance of the system (including capacitor, spark gap, the compact diode, and the return current path) is found to be around $145 \pm 5 \mathrm{nH}$. The PIN diodes are used to detect the $\mathrm{X}$-rays for $\mathrm{Cu}-\mathrm{K} \alpha$ with a Ross filter pair of $17.5 \mu \mathrm{m} \mathrm{Ni}$ and $20 \mu \mathrm{m}$ Co. 
The X-ray emission and the wall plug efficiency in $4 \pi$ geometry is estimated using the relation [16]

$$
\mathrm{Y}=\operatorname{Qexp}(4 \pi) / d \Omega * S(E) * T(E)
$$

Where $Q_{\exp }=\int V d t / R$ (Coulombs) is the difference in the area under the waveforms with two respective filters, $S(E)$ is the average sensitivity of the detector (taken form the Quantrad brochure), $T(E)$ is the average transmission of the filter, $R=50 \Omega$, in the recent experiment, $\mathrm{d} \Omega$ is the solid angle subtended by the detector at the center of the anode.

The variation of $\mathrm{Cu}-\mathrm{K} \alpha$ emission as a function of separation of the electrodes is described in Fig. 3. The highest $\mathrm{Cu}-\mathrm{K} \alpha$ yield in $4 \pi$ geometry, which is recorded at a separation of $3 \mathrm{~mm}$, is $320 \mathrm{~mJ}$, and the corresponding efficiency is $0.035 \%$. Figure 4 shows the variation of total $\mathrm{X}$-ray emission and efficiency against the separation of electrodes. Maximum X-ray emission and wall plug efficiency in $4 \pi$ geometry for interelectrode separation of 3 $\mathrm{mm}$ is $850 \pm 0.05 \mathrm{~mJ}$ and $0.094 \pm 0.01 \%$. When the separation of electrode is reduced from the optimum value, the electrons may penetrate deeper into the target, which may cause enhanced selfabsorption of X-rays, causing reduction in emission.

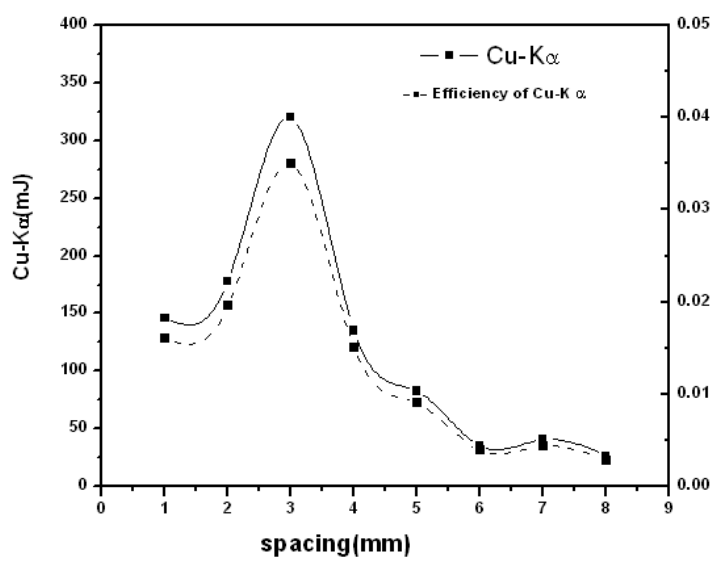

Figure 3. Variation of $\mathrm{Cu}-\mathrm{k} \alpha$ emission along system efficiency versus electrode separation

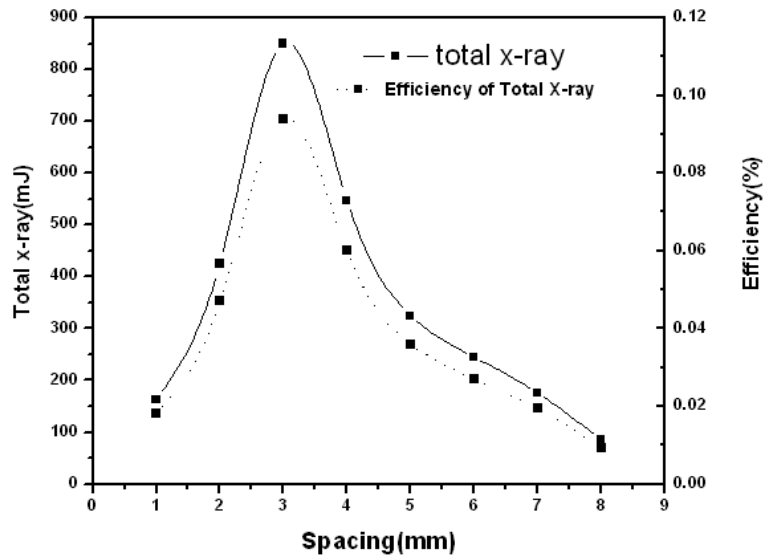

Figure 4. Variation of total $x$-ray emission and system efficiency versus electrode separation.

\section{Conclusions}

A capacitor bank of discharge energy $625 \mathrm{~J}$ energizes a compact diode comprising a flat-plate anode and a sharpedged cathode. The compact diode system is investigated for optimization of X-ray emission by changing the interelectrode spacing which is observed for 3-mm interelectrode spacing. The maximum efficiency of the compact diode for total X-ray emission is found to be $0.094 \%$. The efficiency of the system is expected to be increased further by lowering the parasitic inductance of the system and increasing the charging voltage.

\section{Acknowledgment}

The author is very grateful to Fazli Manan (Ph.D scholar) for his valuable suggestion and guidance in the preparation of this manuscript.

\section{References}

[1] E. Sato, H. Isobe, and F. Hoahino,High-intensity flash x-ray apparatus for biomedical radiography" Rev. Sci. Instrum.Vol $57,1399,1986$.

[2] E. Sato, S. Kimura, S. Kawasaki, K. Takahashi, Y. Tamakawa, and T. Yanagisawa, Repetitive flash x-ray generator utilizing a simple diode with a new type of energy-selective function,Rev. Sci.Instrum, Vol 61, 2343, 1990.

[3] E. Sato, A. Shikoda, S. Kimura, M. Sagae, H. Isobe, K. Takahashi, Y. Tamakawa, T.Yanagisawa, K. Honda, and Y. Yokota, conjunction with an extremely hot cathodeRev. Sci. Instrum. Vol 62, 2115, 1991.

[4] J. I. Levatter and Z. Li, Excited lasers, Rev. Sci. Instrum, Vol 52, 1651, 1981.

[5] I. V. Tomov, P. Chen, and P. M. Rentzepis, Nano- second hard $\mathrm{x}$-ray source for time resolved $\mathrm{x}$-ray diffraction studies Rev. Sci. Instrum. Vol 66, 5214, 1995.

[6] I. L. Spain and D. R. Black, High-pressure apparatus: Comparison of synchrotron and conventional x-ray sources, Rev. Sci. Instrum, Vol 56, 1461, 1985.

[7] H. Milchberg, R. R. Freeman, and S. C. Davey, Advances in Laser Science II. AIP Conf. Proc.Vol 160, 179 (1987).

[8] J. D. Ivers and J. A. Nation, A Compact $1 \mathrm{GW}$ Pulsed Power Source, Rev. Sci. Instrum. Vol 54, 1509 (1983).

[9] H. Bhuyan, S.R. Mohanty, N.K. Neog, S. Bujarbarua, and P.K. Rout, Comparative study of soft $\mathrm{x}$-ray emission characteristics in a low energy dense plasma focus device, J. Appl. Phys. 95, 2975-2981, 2004.

[10] R.S. Rawat, T. Zhang, C.B.L. Phua, J.X.Y. Then, K.A. Chandra, X. Lin, A. Patran, and P. Lee, Effect of insulator sleeve length on soft $\mathrm{X}$-ray emission from a neon-filled plasma focus device, Plasma Sources Sci. Technol. Vol 13, 569-575, 2004.

[11] A. Ikhlef and M. Showronek, IEEE Trans. Plasma Sci.Vol $54,669,1993$. 
[12] A. Shikoda, E. Sato, M. Sagae, T. Oizumi, Y. Tamakawa, and Y. Yanagisawa, "Repetitive flash $\mathrm{x}$-ray generator having a high-durability diode driven by a two-cable-type line pulser Rev. Sci. Instrum. Vol 65, 850, 1994.

[13] M. Zakaullah and J. Worley, X-ray emission from $30 \mathrm{~J}$ Blumlein operated compact diode, J. App. Phys, 88, 2000, 1251

[14] M. Shafiq, S. Hussain, M. Sharif, M. Zakaullah and A.
Waheed, Study of molybdenum K-series line radiation from a low-energy plasma focus, Phys. Lett. A, 302, 2002, 23

[15] J. W. Robison, Handbook of Spectroscopy (Cleveland, OH, CRC1974).

[16] M. Zakaullah, Khalid Alamgir, G. Murtaza and A. Waheed, Efficiency of plasma focus for argon K-series line radiation emission, Plasma Sources Sci. Technol, 9, 2000, 592-596. 